\title{
Crystal structure of $\mathrm{SrC}_{1-x} \mathrm{Mo}_{x} \mathrm{O}_{3-\delta}(0 \leq \mathrm{x} \leq 1)$ perovskites obtained under oxidizing and reducing conditions with potential use as electrodes for intermediate-temperature symmetrical solid-oxide fuel cells
}

\author{
S. Orozco Gil ${ }^{1,2}$, A. L. Larralde², S. A. Larrondo ${ }^{1,3}$, D. G. Lamas ${ }^{2}$ \\ ${ }^{1}$ UNIDEF-MINDEF-CONICET, Departamento de Investigaciones en Sólidos, CITEDEF, J. B. de La Salle 4397, CP 1603 Villa \\ Martelli, Buenos Aires, Argentina, ${ }^{2}$ ITECA-ECyT-UNSAM-CONICET, Laboratorio de Cristalografia Aplicada, Campus Miguelete, \\ Martín de Irigoyen 3100, CP 1650 San Martín, Buenos Aires, Argentina. ${ }^{3}$ Instituto de Investigación e Ingeniería Ambiental, 3iA- \\ UNSAM, Campus Miguelete, Av. 25 de Mayo y Francia, CP1650 San Martín, Buenos Aires, Argentina.
}

sgil@citedef.gob.ar

In this work, $\mathrm{SrCo}_{1-\mathrm{x}} \mathrm{Mo}_{\mathrm{x}} \mathrm{O}_{3-\delta}(0 \leq \mathrm{x} \leq 1)$ powders were synthesized by the gel-combustion method in order to explore two major aspects: the synthesis method and the crystal structure of these systems upon the variation of the Co/Mo relation. Sample $\mathrm{SrCo}_{0.95} \mathrm{Mo}_{0.05} \mathrm{O}_{3-\delta}$, exhibiting a tetragonal phase (space group $\mathrm{P4} / \mathrm{mmm}$ ) at room temperature (RT) was used as the parent compound as it was reported to be a good cathode for intermediate-temperature solid-oxide fuel cells (IT-SOFCs) [1]. The amount of glycine used as fuel in the synthesis route was studied in order to obtain a single-phased material with high homogeneity and reproducibility. Afterward, the relationship between the Co/Mo ratio in the B site of the perovskite was also investigated with the aim of implementing these materials as potential electrodes for intermediate-temperature symmetrical solid-oxide fuel cells (IT-SSOFCs). Thus, both the crystal structure and the reducibility properties of the powders were investigated by X-ray powder diffraction (XPD) and temperatureprogrammed reduction under diluted $\mathrm{H}_{2}\left(\mathrm{H}_{2}\right.$-TPR) techniques respectively. Additionally, scanning electron microscopy (SEM) was performed for the $\mathrm{SrCo}_{0.95} \mathrm{Mo}_{0.05} \mathrm{O}_{3-\delta}$ sample in order to study its morphology.

The $\mathrm{SrCo}_{0.95} \mathrm{Mo}_{0.05} \mathrm{O}_{3-\delta}$ sample synthesized by the addition of a non-stoichiometric amount of glycine, was able to stabilize the desired tetragonal phase as shown in Fig. 1. On the other hand, the undoped $\mathrm{SrCoO}_{3-\delta}$ sample showed the typical hexagonal structure corresponding to the $R 32$ space group. Samples containing $0.1 \leq \mathrm{x} \leq 1 \mathrm{Mo}$, prepared in air flow at RT, presented two additional tetragonal phases (space groups: $I 4 / m$ and $I 4_{l} / a$ ), which correspond to the $\mathrm{Sr}_{2} \mathrm{CoMoO}_{6-\delta}$ double perovskite and the $\mathrm{SrMoO}_{4} \mathrm{scheelite}$ phase respectively, as depicted in Fig. 2. Recent research has shown that this double perovskite material can become a promising ceramic oxide for anode applications in IT-SOFC [2]. Samples calcinated in a $5 \mathrm{~mol} \% \mathrm{H}_{2}$ in Ar flow $\left(50 \mathrm{~cm}^{3}\right.$ (STP) $\left.\mathrm{min}^{-1}\right)$ during the $\mathrm{H}_{2}$-TPR experiments showed that, those with the lowest Mo content presented some reduction peaks at 275,390 and $825^{\circ} \mathrm{C}$; and the ones with the highest Mo content were partially reduced at $900{ }^{\circ} \mathrm{C}$. In the latter, a cubic phase was stabilized at RT (Pm-3m space group), which has been considered an ideal phase for its use as IT-SOFCs anode materials [3], meaning a big possibility to obtain other materials at intermediate Co/Mo compositions with optimal properties for IT-SSOFCs electrodes.

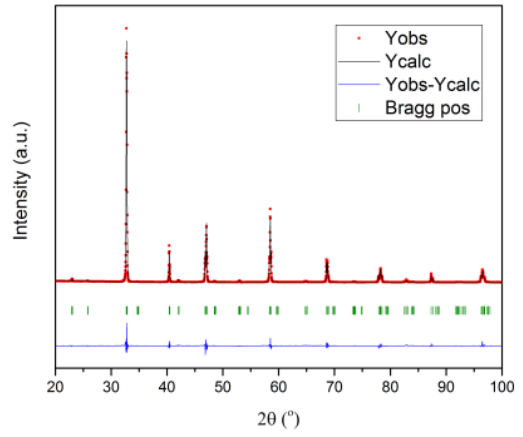

Figure. 1. Rietveld refinement for $\mathrm{SrCo}_{0.95} \mathrm{Mo}_{0.05} \mathrm{O}_{3-\delta}$ in the $P 4 / \mathrm{mmm}$ space group.

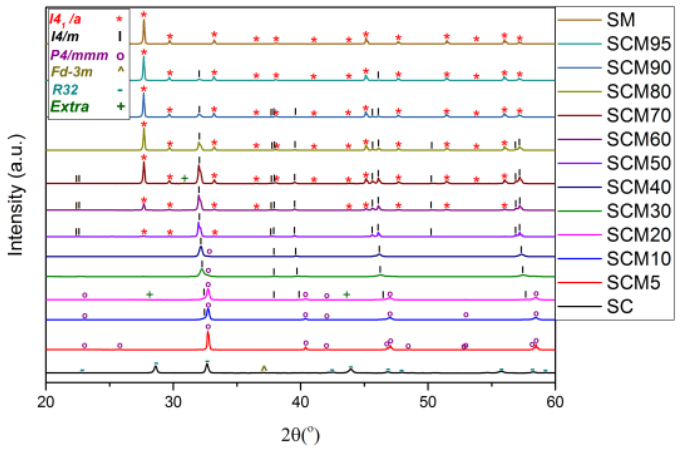

Figure. 2. XRD patterns for $\mathrm{SrCo}_{1-\mathrm{x}} \mathrm{Mo}_{\mathrm{x}} \mathrm{O}_{3-\delta}(0 \leq \mathrm{x} \leq 1) \mathrm{RT}$, air.

[1] Aguadero, A., Perez-Coll, D., Alonso, J. A., Skinner, S. J. \& Kilner, J. A. (2012). Chem. Mater. 24, 2655.

[2] Witt, S. E., Allen, A. J., Kuzmenko, I., Holtz, M. \& Young, S. (2020). ASC Appl. Energy Mater. 3, 6, 5353.

[3] Martínez-Coronado, R., Alonso, J. A. \& Fernández-Díaz, M. T., (2014). J. Power Sources 258, 76.

Keywords: perovskites; SOFCs; IT-SSOFCs; XPD; Rietveld refinement

Acta Cryst. (2021), A77, C755 